Article

\title{
Spatial Pattern of Forest Carbon Storage in the Vertical and Horizontal Directions Based on HJ-CCD Remote Sensing Imagery
}

\author{
Kaisheng Luo $\mathbb{D}$ \\ School of Remote Sensing and Geomatics Engineering, Nanjing University of Information Science and \\ Technology, Nanjing 210044, China; 002872@nuist.edu.cn; Tel.: +86-188-6095-7185
}

Received: 15 January 2019; Accepted: 27 March 2019; Published: 2 April 2019

\begin{abstract}
To provide a comprehensive understanding of the spatial distribution of forest carbon reserves, this study explores carbon storage and its spatial pattern in the horizontal and vertical directions on a provincial scale using HJ-CCD remote sensing imagery. Results show that carbon storage in the forests of Hubei Province was 784.46 Tg. In the horizontal direction, Enshi Prefecture contributed the most, with a contribution rate of $22.01 \%$, followed by Yichang (18.74\%), Shiyan (15.21\%), and Xiangfan (10.61\%). Coniferous forests contributed the most to the total carbon reserves of the forests, with a contribution rate of $71.34 \%$, followed by broadleaf forests $(25.36 \%)$, and mixed forests $(3.30 \%)$. In the vertical direction, the environmental difference in the vertical direction of the forest ecosystem led to the obvious stratification of carbon storage in the vertical direction, that is: soil layer $>$ tree canopy layer $>$ shrub layer $>$ litter layer. The soil layer had the largest carbon storage, contributing $76.63 \%$, followed by the tree canopy layer $(19.05 \%)$, shrub layer $(2.39 \%)$, and litter layer $(1.93 \%)$. The different contributing layers of coniferous, broadleaf, and mixed forests to carbon storage followed the same order: soil layer $>$ tree canopy layer $>$ shrub layer $>$ litter layer.
\end{abstract}

Keywords: forest carbon storage; vertical direction; horizontal direction; pattern; forest layer

\section{Introduction}

As the main body of the land ecosystem, global forests annually absorb $2.4 \mathrm{Pg} C$ from the atmosphere [1]. Approximately $10 \%-20 \%$ of atmospheric $\mathrm{CO}_{2}$ emissions that are attributed to land-use change, especially deforestation and forest degradation, forest ecosystem carbon sequestration capacity and changes exert a considerable effect on the conversion of carbon source and sink functions of terrestrial ecosystems [2,3]. In May 2018, the global average monthly concentration of $\mathrm{CO}_{2}$ reached $410.26 \mathrm{mg} / \mathrm{L}$ [4]. With the continuous increase in atmospheric $\mathrm{CO}_{2}$ concentration against the background of global warming, the accurate estimation of forest ecosystem carbon and its characteristics is related to whether the atmospheric $\mathrm{CO}_{2}$ concentration can be reduced and the global warming trend can be curbed $[5,6]$. Thus, the forest carbon estimation has become a focus in the study of terrestrial carbon cycles [1,7].

Changes in the forest and atmospheric carbon cycles have become a global problem $[4,8]$. A quantitative study of the carbon reserves of forest ecosystems should start on a large regional scale [8]. The traditional methods based on site observation or statistical data requires considerable amounts of manpower, material resources, and financial resources, and yet the results still lack timeliness because of the long period of large-scale data acquisition. More importantly, the reliability of statistical data and the representativeness of observation data from point to surface are questionable. By contrast, remote sensing methods are stable, continuous, real-time, low cost, and large scale, and can well reflect the regional-scale distribution characteristics of the forest ecosystem carbon and improve the accuracy of 
estimating forest ecosystem $\mathrm{CO}_{2}$ sources and sinks; thus, remote sensing has become an important tool for carbon storage estimation $[9,10]$. Estimating the carbon storage in a large area is nearly impossible when using high-resolution images, because of the exorbitant cost. However, low-resolution images yield rough results; thus, the use of medium-resolution remote sensing images is a good choice in a large study area $[9,10]$.

Over the past 20 years, many scholars have studied forest carbon and made important achievements; however, their studies have mainly focused on the national scale, and systematic studies on forest carbon on the province scale are still few [11,12]. Forest carbon storage remarkably varies across provinces because of the vast territory, large regional spatial differences, complex natural environment, and diverse forest ecosystem [13]. Furthermore, forest carbon storage is affected by scale, and the values of provincial carbon storage vary across different research scales. China has a vast territory, large regional spatial differences, complex natural environments, and diverse forest resources. In China, the value for one province, such as Hubei Province in the south, obtained on the national scale is considerably lower than that obtained on the provincial scale [14,15]. Moreover, a province is an important administrative unit for the implementation of carbon emission and forest management measures. Therefore, the carbon reserves and their characteristics should be further studied on the provincial scale.

Forest ecosystems not only have the spatial rule in the horizontal direction but also have the stratification rule in the vertical direction [16]. A forest ecosystem is generally divided into the arbor, shrub, herb, litter, and soil layers in the vertical direction [5]. With the differences in the environment, the ecological activities and ecological processes in forest ecosystems greatly differ [5,17], resulting in biomass and carbon storage differences and stratification. Vertical forest stratification is the adaptation process of the vegetation to the environmental heterogeneity of the community and is also one of the basic characteristics of the plant community. However, existing studies on the carbon storage in forest ecosystems mainly focus on a certain layer, especially the tree canopy layer and soil layer. Specialized studies on the carbon storage in various forest layers in the vertical direction are still rare. Furthermore, previous related studies have been based on points, such as sites or samples, rather than on continuous surfaces. Site-specific results cannot be generalized to large-scale regions. Therefore, the following issues require definitive answers: the rule governing carbon storage in the vertical direction on continuous surfaces; the contribution of each layer to carbon storage in forest ecosystems; the contribution of one layer of different forest types to the carbon reserves of forest ecosystems; and the differences among the contributions of different layers. Therefore, the distribution and contribution of forest ecosystem carbon reserves in the vertical stratification structure should be further studied.

The majority of related studies have focused on carbon storage in temperate and tropical forests in the north, whereas few have investigated the carbon density of subtropical forests $[7,10,13,14]$, particularly forests in Hubei Province. Hubei Province is located in the climate zone that connects the subtropical zone to the warm temperate zone and is one of the regions that is highly sensitive to global climate change [18]. Evergreen coniferous, deciduous broadleaf, and mixed forests are widely distributed in this region [16]. However, the contributions and spatial distributions of various forest carbon sink systems currently remain unclear despite their key role in the formulation of strategies for adaption to global climate change; the planning of ecological engineering efforts, such as afforestation; and the accurate assessment of the spatial patterns of carbon storage by relevant regional departments and decision-makers.

To answer these questions, this study used remote sensing to conduct an investigation of the carbon storage in forest ecosystems on the provincial scale. This study mainly aims to (1) estimate the total carbon storage and the provincial-scale spatial pattern and identify the maximum contribution areas; (2) quantify the contributions of different layers to the total carbon storage and clarify the patterns of carbon storage in the different layers of forest ecosystems; and (3) quantify the contributions of different forest layers to the carbon storage in forest ecosystems and uncover the regulation mechanism. 


\section{Materials and Methods}

\subsection{Study Area}

Hubei Province is located in the Yangtze River Shelter Forest in the central part of mainland China. It lies between $108^{\circ} 21^{\prime} 42^{\prime \prime}$ and $116^{\circ} 07^{\prime} 50^{\prime \prime} \mathrm{E}$ and between $53^{\circ} 29^{\prime} 01^{\prime \prime}$ and $33^{\circ} 47^{\prime} 06^{\prime \prime} \mathrm{N}$, covering a total area of $18.59 \times 10^{4} \mathrm{~km}^{2}$ (Figure 1). The terrain is surrounded by mountains to the east, west, and north, with a low level in the middle and slightly open to the south. Mountains, hills, and plain lakes account for $56 \%, 24 \%$, and $20 \%$, respectively [16]. The climate belongs to the subtropical monsoon climate zone, with an average annual temperature of $15-17{ }^{\circ} \mathrm{C}$, annual temperature range of $3.2-39{ }^{\circ} \mathrm{C}$, and annual rainfall of 800-1600 mm. The soil in Hubei Province is mainly red, yellow, brown, and dark-brown. Red soil is mainly distributed in low mountains, hills, or ridges with heights less than $800 \mathrm{~m}$ in southeastern Hubei Province and in hills, hilly terraces, or basins below $500 \mathrm{~m}$ in southwestern Hubei Province. Yellow soil is distributed in a mountainous area of heights of $500 \mathrm{~m}$ to $1200 \mathrm{~m}$ in regions southwest of Hunan Province. Brown soil is mainly distributed in the western mountains, and dark brown soil is distributed in mountains above altitudes of approximately $2200 \mathrm{~m}$ [18]. Forest vegetation coverage is extensive. Forest vegetation mainly comprises coniferous, broadleaf, and mixed forests. Coniferous forests are largely composed of evergreen Pinus massoniana with little to no deciduous coniferous forests. Mixed forests are dominated by coniferous forests [16]. The main tree species are Pinus massoniana, Cunninghamia lanceolata, P. armandii, Quercus acutissima, Q. variabilis, Q. aliena var. acuteserrata, Cinnamomum camphora, Castanopsis sclerophylla and Cyclobalanopsis glauca [18]. The main soil types of coniferous forest are yellow, red, and yellow-brown. In addition, the main soil types of broad-leaved and mixed forests are red and yellow-brown, respectively [18,19].

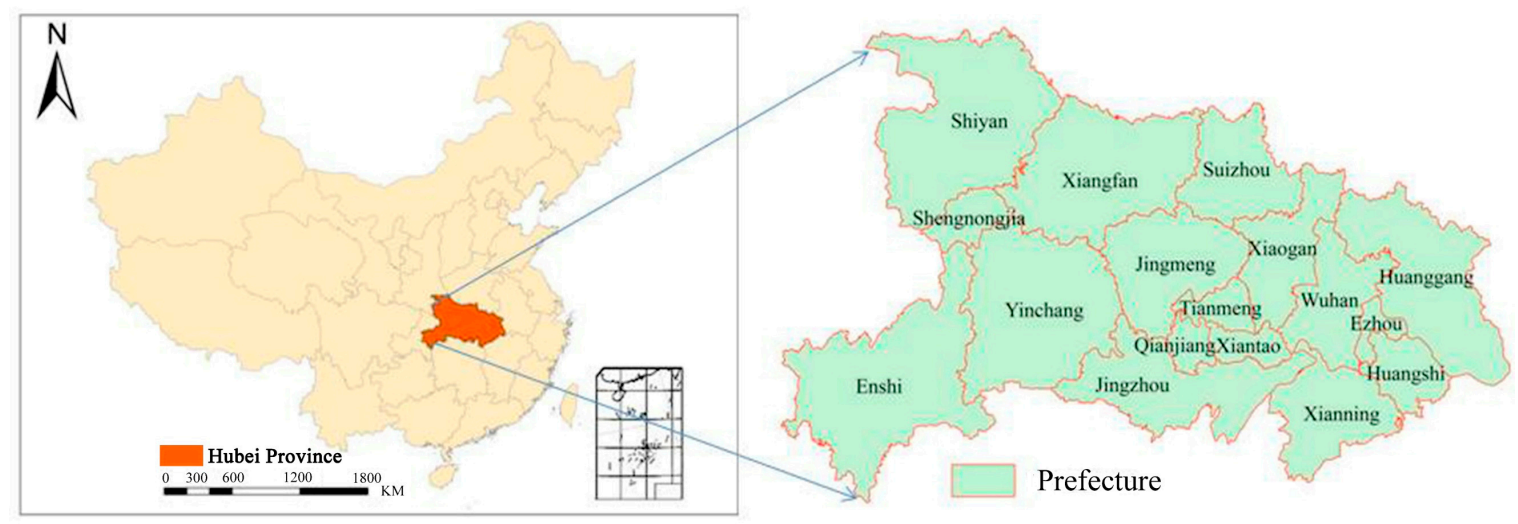

Figure 1. Location of the study area.

\subsection{Data Preparation and Processing}

\subsubsection{Data Source}

In this study, the wide-band and multi-spectral camera (CCD) imagery of Chinese Huanjing satellite (HJ-CCD) and carbon density data taken from the report published by Wang et al. (http: / / zkxb.csuft.edu.cn/oa/pdfdow.aspx?Sid=201510017) [19] were used as the main data source. The HuanJing A/B satellite (HJ-1A/B) satellites equipped with a CCD camera, which had four bands with a resolution of $30 \mathrm{~m}$, were launched in September 2008. The main parameters of the HJ-CCD images are shown in Table 1. The revisit period of HJ-1A/B satellites is 2-3 d [20]. In consideration of the seasonal variation of vegetation and the objective of achieving high-classification accuracy, we used multi-season (i.e., spring, summer, and winter) HJ-CCD images in this study. The image data included HJ-CCD images in spring, summer, and winter, and the auxiliary data included a digital elevation model (DEM) map and an aspect map. To reduce the spectral error caused by the seasonal angle of the sun or vegetation phenology as well as avoid the influences of clouds and fog, we selected 
23 scene images, which included 7 scene images in spring, 7 scene images in summer, and 9 scene images in winter. Amongst them, the HJA-CCD imagery consisted of 9 scenes, and the HJ1B-CCD imagery consisted of 14 scenes, as shown in Table 2. The HJ-CCD data were downloaded from the China Centre for Resources Satellite Data and Application (http:/ /www.cresda.com/CN/), the DEM map was obtained from the United States Geological Survey website (https://www.usgs.gov), and the aspect map was generated by DEM in ERDAS IMAGINE 9.2 software.

Table 1. The main parameters of the wide-band and multi-spectral camera (CCD) imagery of Chinese Huanjing satellite (HJ-CCD).

\begin{tabular}{lcc}
\hline \multicolumn{1}{c}{ Spectral Band } & Spatial Resolution & Spectral Range \\
\hline B1: blue & $30 \mathrm{~m}$ & $0.43-0.52 \mu \mathrm{m}$ \\
B2: green & $30 \mathrm{~m}$ & $0.52-0.60 \mu \mathrm{m}$ \\
B3: red & $30 \mathrm{~m}$ & $0.63-0.69 \mu \mathrm{m}$ \\
B4: near-infrared & $30 \mathrm{~m}$ & $0.76-0.90 \mu \mathrm{m}$ \\
\hline
\end{tabular}

Table 2. HJ-CCD remote sensing images used in this study.

\begin{tabular}{ccc}
\hline \multicolumn{1}{c}{ Winter Images } & Spring Images & Summer Images \\
\hline HJ1B-CCD1-5-76-20100101 & HJ1B_CCD1-5-76-20100316 & HJ1B-CCD2-5-76-20100617 \\
HJ1B-CCD1-2-76-20101210 & HJ1B-CCD1-2-76-20100408 & HJ1B-CCD1-2-76-20100803 \\
HJ1A-CCD2-2-80-20100102 & HJ1A-CCD1-454-80-20100317 & HJ1A-CCD2-457-80-20100920 \\
HJ1A-CCD1-2-80-20101208 & HJ1B-CCD2-1-80-20100524 & HJ1B-CCD1-454-80-20100818 \\
HJ1A-CCD2-2-80-20100102 & HJ1A-CCD2-2-80-20100317 & HJ1B-CCD1-2-80-20100803 \\
HJ1B-CCD2-456-80-20101209 & HJ1B-CCD2-2-80-20100317 & HJ1B-CCD2-5-80-20101016 \\
HJ1B-CCD2-457-80-20101217 & HJ1A-CCD1-7-80-20100326 & HJ1A-CCD2-5-77-20100615 \\
HJ1B-CCD2-5-80-20101202 & HJ1B-CCD1-5-76-20100318 & \\
HJ1A-CCD2-6-80-20101208 & & \\
\hline
\end{tabular}

\subsubsection{Data Processing}

The data pre-processing mainly included projection transformation, image mosaicking and clipping, geometric correction, atmospheric correction and segmentation. The WGS84 coordinate system and universal transverse mercator (UTM) projection method were adopted for data unification. Using the thematic mapper data of Landsat satellite (Landsat TM) as the reference image, we completed the geometric precision correction by quadratic polynomial transformation and bilinear interpolation. The coverage of the HJ1A/B satellite is $360 \mathrm{~km}^{2}$, the error of the sub-satellite point is minimal, and the surrounding deformation is large. Accordingly, the images in the alpine and canyon zones were initially divided horizontally and subsequently undergo orthorectification. On the basis of the calibration parameters provided by the China Centre for Resources Satellite Data and Application, we completed the atmospheric correction of the images.

Considering the processing capability of the computer used and the characteristics of the underlying surface, the pre-processed HJ-CCD data of Hunan Province were divided into 25 small splits and coded (Figure 2a). 


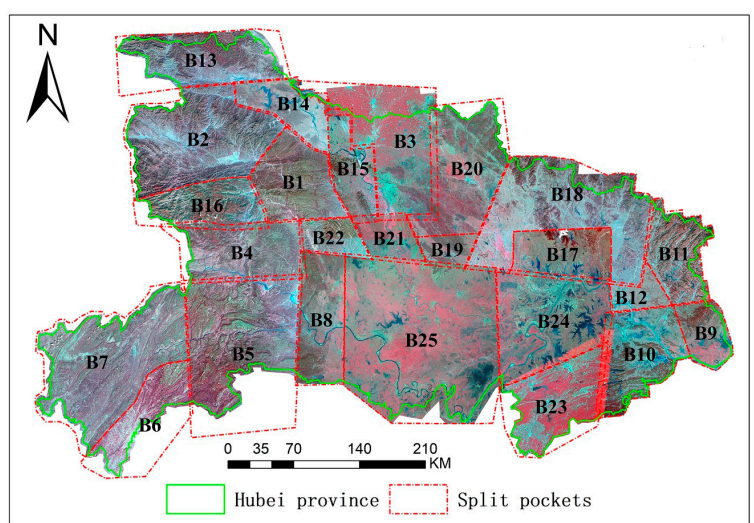

(a)

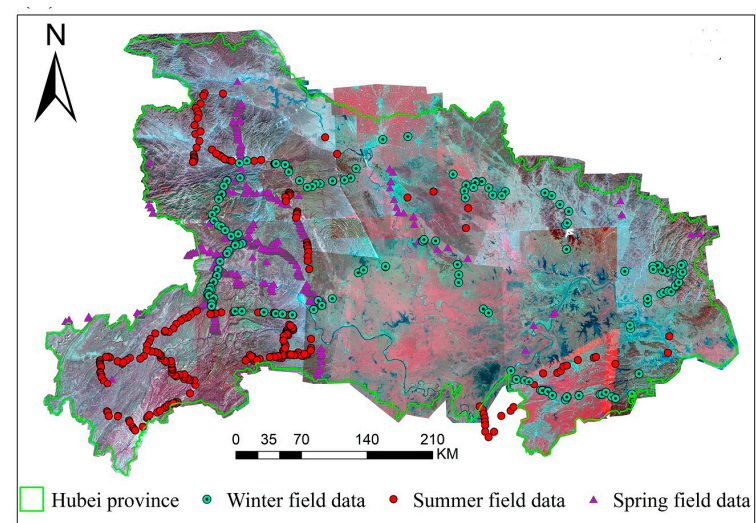

(b)

Figure 2. Divided splits of the study site (a) and the spatial distribution of the field samples in spring, summer, and winter (b).

\subsubsection{Field Data}

Field samples were used to verify the accuracy of the forest classification results. In 2010, we conducted field sampling thrice across Hubei Province in spring (march), summer (June), and winter (December), each lasting one month. In the process of sampling, we used handheld GPS devices to obtain the latitudinal and longitudinal values. We also measured and recorded the various attributes of each forest sample, including the forest category, main tree species, slope gradient, and surrounding conditions. In the design of the route, we considered the image characteristics and traffic accessibility, and the field sampling was more intensive in the broken landscape area for better image interpretation and classification (Figure 2b). In this study, a total of 1080 field samples were finally collected, including 651 in spring, 351 in summer, and 178 in winter.

We adopted the carbon density $\left(\mathrm{t} \cdot \mathrm{hm}^{-2}\right)$ results of Wang et al. [19] for arbor, shrub, litter, and soil layers [19]. Wang et al. [19] sampled 251 field plots, each with an area of $667 \mathrm{~m}^{2}(25.82 \mathrm{~m} \times$ $25.82 \mathrm{~m}$ ), across Hubei Province in 2009 to obtain the carbon densities of the arbor, shrub, litter, and soil layers [19]. The results of the present study were verified using the calculation results of Pang et al. [21] for carbon storage in the tree canopy layer [21]. In 2012, Pang et al. [21] designed 10, 16, 10, 11, 13, and 4 sample plots in Enshi, Yichang, Shiyan, Xiangfan, Huanggang, and Xiaogan, respectively. The plot for each prefecture had an area of $667 \mathrm{~m}^{2}(25.82 \mathrm{~m} \times 25.82 \mathrm{~m})$. The carbon storages in the tree canopy layers of the coniferous forests in the abovementioned prefectures were obtained on the basis of the measurement results for field plots [21].

\subsection{Calculation Method for Carbon Storage}

The calculation of carbon storage in this study was divided into two steps. First, the refined information about forests was extracted using the HJ-CCD images to obtain the area of various forest types in Hubei Province, then the forest carbon storage was calculated. The calculation formula for total forest carbon storage is

$$
S=\sum_{i=1}^{4} S_{i}(i=1,2,3)
$$

In Equation (1), $S$ is the total forest carbon storage (Tg) in a region, and $S_{i}$ is the carbon storage $(\mathrm{Tg})$ in the $i$ th forest category in a region. In the Hubei Province, forest category includes broadleaf, coniferous or mixed forest, whose classification indicators adopted the study results of Zhang et al. [22], as summarized in Table S1 in the Supplementary Material (http:/ / www.ecologica.cn/stxb/ch/reader/ create_pdf.aspx?file_no=stxb201310102431\&flag=\&journal_id=stxb\&year_id=2014).

The carbon storage $\left(S_{i}\right)$ of the $i$ th forest category in a region was calculated as follows

$$
S_{i}=S_{i a}+S_{i s}+S_{i l}+S_{i o}=A_{i}\left(q_{i a}+q_{i s}+q_{i l}+q_{i o}\right) .
$$


In Equation (2), $S_{i a}, S_{i s}, S_{i l}$, and $S_{i o}$ are the carbon storage amounts (Tg) of the tree canopy layer, shrub layer, litter layer, and soil layer in the $i$ th forest category respectively; $q_{i a}, q_{i s}, q_{i l}$, and $q_{i o}$ are the carbon densities or the carbon storage per unit area $\left(\mathrm{t} \cdot \mathrm{hm}^{-2}\right)$ of the tree canopy layer, shrub layer, litter layer, and soil layer in the $i$ th forest category, respectively. The arbor and shrub layers are distinguished by diameter at breast height (DBH) [19]. As in most countries in the world, the breast height is $1.3 \mathrm{~m}$. If the vegetation height is less than $1.3 \mathrm{~m}$, the $\mathrm{DBH}$ value is replaced by the base diameter [19]. If the $\mathrm{DBH}$ of the vegetation is greater than or equal to $3 \mathrm{~cm}$, then it is classified into the tree canopy layer. If the DBH of the vegetation is $1-3 \mathrm{~cm}$, it is classified into the shrub layer [19]. In Hubei Province, the litter layer is relatively evident; thus, these layers can be completely distinguished visually [19]. The litter layer is generally $1-20 \mathrm{~cm}$ in height, correspondingly. The depth of the soil layer used in this study was $0-100 \mathrm{~cm}$ [19]. The values of $q_{i a}, q_{i s}, q_{i l}$, and $q_{i o}$ adopt the measurement results from the field samples $\left(\mathrm{t} \cdot \mathrm{hm}^{-2}\right)$ as shown in Table 3.

Table 3. Carbon density $\left(\mathrm{t} \cdot \mathrm{hm}^{-2}\right)$ of tree canopy layer, shrub layer, litter layer, and soil layer in different forest types in Hubei Province [19].

\begin{tabular}{lcccc}
\hline \multicolumn{1}{c}{ Forest Types } & Tree Canopy Layer & Shrub Layer & Litter Layer & Soil Layer \\
\hline Broadleaf forests & 37.8948 & 4.7637 & 3.8293 & 152.4676 \\
Coniferous forests & 106.5977 & 13.4001 & 10.7718 & 428.8899 \\
Mixed forests & 4.9222 & 0.6188 & 0.4974 & 19.8046 \\
\hline
\end{tabular}

Wang et al. [19] considered the distribution of forests in Hubei Province and arranged 251 standard field sample plots of various forest types. The plots were distributed as follows: 30 in Yichang, 25 in Shiyan, 26 in Xianning, 29 in Enshi, 32 in Huanggang, 5 in Huangshi, 5 in Jingzhou, 66 in the Shennongjia forest region, 2 in Wuhan, 26 in Xiangyang, and 5 in Xiaogan [19]. The specifications of the standard plots were $25.82 \mathrm{~m} \times 25.82 \mathrm{~m}$. Tree species with a diameter of $5 \mathrm{~cm}$ or more were measured per wood in the sample plot. The tree survey mainly included species name, number, diameter, and height. A $2 \mathrm{~m} \times 2 \mathrm{~m}$ shrub quadrate was set at the northwest, northeast, and southeast corners of each tree quadrate, and the dominant species (diameter $<5 \mathrm{~cm}$ ), coverage, plant quantity (height $<50 \mathrm{~cm}$ ), and average height were investigated [19]. At the same time, three standard shrubs with average sizes were selected in each sample plot, and their fresh and dry branch, leaf, and underground root system weights were measured through the whole plant harvesting method. Shrubs with 1-2 clumps of average canopy width were selected in the sample plot if they were clustered. The samples were mixed and then transported to the laboratory for the measurement of the moisture content of each organ. A $1 \mathrm{~m} \times 1 \mathrm{~m}$ litter sample square was set in the center of each shrub sample quadrate for the investigation of litter thickness. All types of litter, such as various dead mixtures of branches, leaves, fruits, grasses, and semi-decomposed plant parts, in the sample square were collected. Non-organic materials, such as gravel and soil, were removed and weighed. The mixed samples were transported to the laboratory. Forest biomass was obtained by using the measured data for the sample plots and forest layers. Forest carbon storage can be calculated by multiplying biomass by the conversion coefficient (carbon mass fraction of dry matter) [19]. Wang et al. [19] used a conversion coefficient of 0.5, which is currently the international standard. Carbon density $\left(\mathrm{Tg} \cdot \mathrm{hm}^{-2}\right)$ can be obtained by dividing carbon storage (Tg) by area $\left(\mathrm{hm}^{2}\right)$ (Table 3) [19].

\subsection{Calculation Method for Contribution}

The contribution of each type of forest or each forest layer to carbon storage is expressed by the ratio of the carbon reserves of a certain type of forest or forest layer to the total carbon reserves of Hubei Province. The formula is as follows

$$
C_{i}=\frac{S_{i}}{S} \times 100 \quad(\mathrm{i}=1,2,3)
$$


In Equation (3), $C_{i}$ is the contribution of the $i$ th forest or the $i$ th layer to carbon storage (\%), $S_{i}$ is the carbon storage in the $i$ th forest or the $i$ th layer $(\mathrm{Tg})$, and $S$ is the total carbon storage $(\mathrm{Tg})$.

\subsection{Information Extraction Method for the Types of Forest}

Previous researchers have established numerous forest classification systems in accordance with research purposes, areas, and objects. Although these classification systems are beneficial for furthering specific research purposes, they restrict the sharing of classification data and the comparability of different results. Therefore, in this study, a method for forest classification in reference to the land-use/cover classification system established by Zhang et al. [22] for international carbon estimation was adopted to increase the universality of the research results and the comparability of the present work with other studies [22]. Table S1 provides a list of specific forest classification indicators and their categories.

In this study, we initially extracted the forest information by using the object-based image analysis (OBIA) technique and subsequently obtained the area and spatial distribution of every type of forest. Depending on the minimum basic unit, remote sensing extraction methods for land-cover information can be generally divided into the traditional pixel-based method and OBIA technique. The OBIA technique, which has revolutionized the traditional pixel-based method, is based on the classification unit, that is, an object with physical meaning, or a set of adjacent pixels with homogeneity [23,24]. The OBIA technique can use the features of a spectrum, space, texture, spatial structure, shape, and other characteristics in the process of extracting land-use information so as to improve the accuracy of the extracted land-use information considerably; consequently, this technique is gradually becoming a next-generation classification method [23,25].

After completing the geometric correction and atmospheric correction of the HJ-CCD images in the ERDAS software, the fine extraction of forest information was performed in the eCognition software platform. Firstly, a region merge algorithm was used to conduct the multi-scale segmentation of the image data [26], and consequently, we obtained the classified primitive, which is the object. Secondly, we used the decision tree (binary decision tree) classification and selected the appropriate features to extract forest information stepwise (Figure 3). Finally, we used the confusion matrix method to evaluate the extraction accuracy by using the field samples. Image segmentation scale, decision tree, and extraction feature threshold were adjusted in accordance with the feedback of extraction accuracy to ensure the high accuracy of extraction results.

We first divided the segmented images into vegetation and non-vegetation by using the summer NDVI $\left(N D V I_{s}\right)$. Subsequently, we divided the vegetation into forest and non-forest by the cumulative NDVI (ANDVI). The forests were divided into deciduous forest and evergreen forest. In a deciduous forest, the leaves fall off in winter and the amount of biomass considerably fluctuates in a year. The opposite condition occurs in an evergreen forest. Therefore, the difference was characterized by differential NDVI (DNDVI), then two types of forest were extracted. In the study area, an evergreen forest was also called a coniferous forest, because all evergreen forests are coniferous forests. The mixed forest in the study area was mainly deciduous; thus, it belongs to the deciduous forest type. The deciduous degrees of a broadleaf forest are different from those of a mixed forest. Field investigation revealed that broadleaf and mixed forests are distributed vertically along mountain height and aspect. Therefore, the winter NDVI $\left(N D V I_{w}\right)$, DEM and aspect indicators were comprehensively used to distinguish both. The calculation formulas of $N D V I_{S}$, DNDVI, and ANDVI are

$$
N D V I_{S}=\left(N I R_{S}-R_{s}\right) /\left(N I R_{s}+R_{s}\right)
$$

In Equation (4), $N D V I_{S}$ is the normalized vegetation index of the HJ-CCD summer images, and $N I R_{S}$ and $R_{S}$ are the near-infrared band and red band of the HJ-CCD summer images, respectively.

$$
D N D V I=N D V I_{s}-N D V I_{w}=\left(N I R_{s}-R_{s}\right) /\left(N I R_{s}+R_{s}\right)-\left(N I R_{w}-R_{w}\right) /\left(N I R_{w}+R_{w}\right)
$$




$$
\begin{aligned}
A N D V I & =N D V I_{s p}+N D V I_{s}+N D V I_{w} \\
& =\left(N I R_{s p}-R_{s p}\right) /\left(N I R_{s p}+R_{s p}\right)+\left(N I R_{s}-R_{s}\right) /\left(N I R_{s}+R_{s}\right) \\
& +\left(N I R_{w}-R_{w}\right) /\left(N I R_{w}+R_{w}\right)
\end{aligned}
$$

In Equations (5) and (6), ANDVI is the sum of the annual NDVI value; $N D V I_{s p}, N D V I_{s}$, and $N D V I_{w}$ are the NDVIs of the HJ-CCD spring images, summer images, and winter images, respectively; $N I R_{s p}, N I R_{s}$, and $N I R_{w}$ are the near-infrared bands of the HJ-CCD spring images, summer images, and winter images, respectively; and $R_{s p}, R_{s}$, and $R_{w}$ are the red bands of the HJ-CCD spring images, summer images, and winter images, respectively.

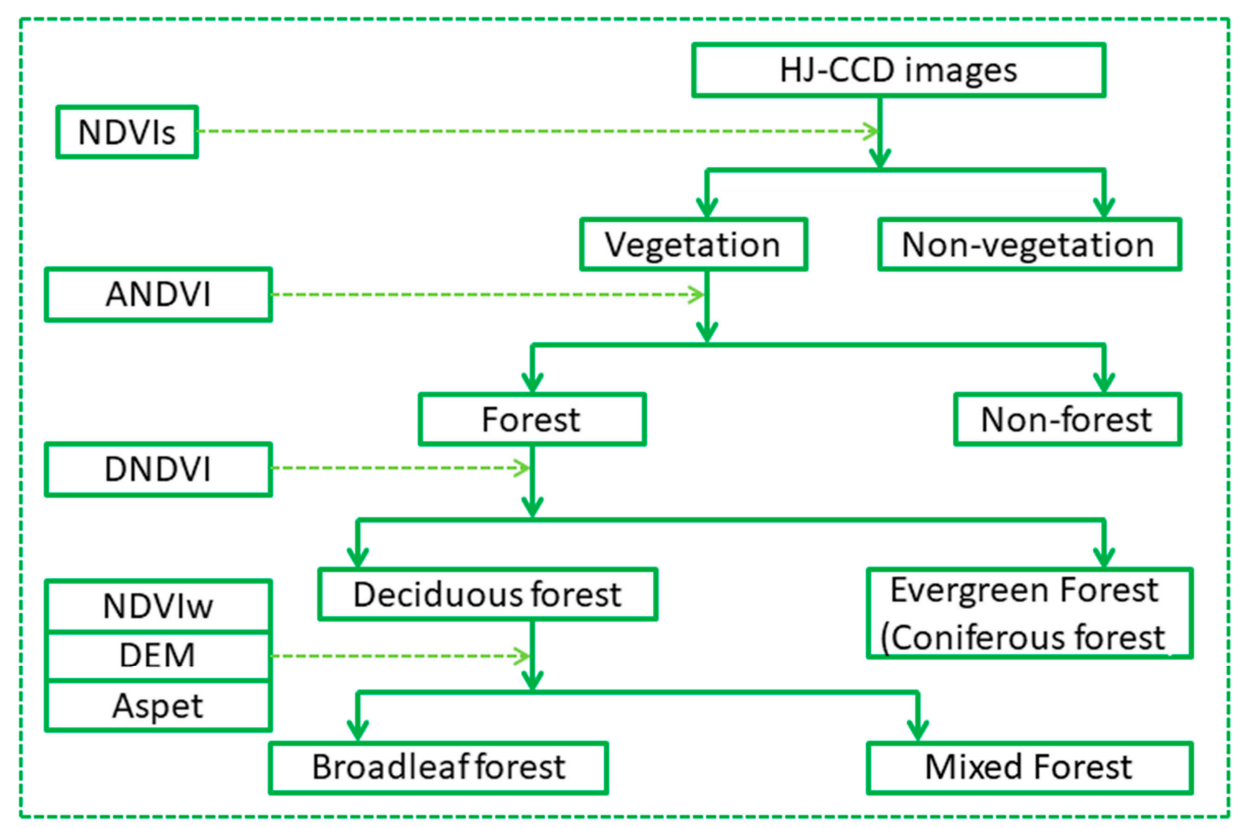

Figure 3. Binary decision tree and classification indices.

\subsection{Accuracy Verification}

A confusion matrix (Table 4) was applied to verify the extraction results of second-level forest information with 1080 field samples. The assessment indicators were above the thresholds of accuracy and Kappa coefficient [27]. Large values over the accuracy and Kappa coefficient were indicative of superior results for forest information extraction [27].

$$
\begin{gathered}
O A=\sum_{i=1}^{n} p_{i i} / N \\
K V=\frac{N \sum_{i=1}^{r} x_{i i}-\sum_{i=1}^{r}\left(x_{i+}+x_{+i}\right)}{N^{2}-\sum_{i=1}^{r}\left(x_{i}+x_{+i}\right)}
\end{gathered}
$$

where $r$ and $x_{i i}$ are the total number of columns (total number of categories) of the confusion matrix and the number of objects in the $i$ th row and $i$ th column of the confusion matrix (number of correct extraction), respectively; $x_{i+}$ and $x_{+i}$ are the numbers of the $i$ th row and $i$ th column, respectively; and $N$ pertains to the total number of field samples used for accuracy evaluation [27]. 
Table 4. Confusion matrix [27].

\begin{tabular}{lcccccc}
\hline \multirow{2}{*}{ Measured Data Type } & \multicolumn{5}{c}{ Measured Data Type } & \multirow{2}{*}{ Sum of Measured Data } \\
\cline { 2 - 6 } & $\mathbf{1}$ & $\mathbf{2}$ & $\ldots$ & $\ldots$ & $\boldsymbol{n}$ & \\
\hline 1 & $p_{11}$ & $p_{21}$ & $\ldots$ & $\ldots$ & $p_{n 1}$ & $p_{+1}$ \\
2 & $p_{12}$ & $p_{22}$ & $\ldots$ & $\ldots$ & $p_{n 2}$ & $p_{+2}$ \\
$\ldots$ & $\ldots$ & & $\ldots$ & $\ldots$ & $\ldots$ & $\ldots$ \\
$\ldots$ & $\ldots$ & & $\ldots$ & $\ldots$ & $\ldots$ & $\ldots$ \\
$n$ & $p_{1 n}$ & $p_{2 n}$ & $\ldots$ & $\ldots$ & $p_{n n}$ & $p_{+n}$ \\
Sum of measured data & $p_{1+}$ & $p_{2+}$ & $\ldots$ & $\ldots$ & $p_{n+}$ & $N$ \\
\hline
\end{tabular}

Carbon storage results were evaluated through the relative error method. Small absolute values of relative error reflect good carbon storage assessment results. Given the limitations of measured carbon reserve data, the present results could only be verified by using the results for the carbon storage of the tree canopy layer of a coniferous forest calculated by Pang et al. [21] on the basis of field sample data collected across the Enshi, Yichang, Shiyan, Xiangfan, Huanggang, Jingmeng, Xiaogan, Wuhan, and Jingzhou prefectures.

$$
E=\frac{f_{\mathrm{c}}-f_{\mathrm{m}}}{f_{\mathrm{m}}} \times 100 \%
$$

where $E$ represents the relative error, $f_{\mathrm{c}}$ is the carbon storage obtained in the present study, and $f_{\mathrm{m}}$ represents the carbon storage value calculated based on the field-measured data published by Pang et al. [21].

\section{Results}

\subsection{Accuracy Evaluation of the Results}

On the basis of the collected field samples, the accuracy of the classification result was quantitatively evaluated by the confusion matrix method. The overall accuracy of the forest extraction results was 93.14\%, and the Kappa coefficient was 0.87 (Table 5), indicating that the classification results presented high precision and can meet the requirements of this study.

Table 5. Accuracy evaluation result of forest information extraction based on the confusion matrix.

\begin{tabular}{llllll}
\hline \multicolumn{1}{c}{ Types of Forest } & Broadleaf Forests & Coniferous Forests & Mixed Forests & Other Land Cover & Sum of Samples \\
\hline Broadleaf forests & 231 & 1 & 14 & 8 & 254 \\
Coniferous forests & 9 & 672 & 26 & 6 & 713 \\
Mixed forests & 2 & 6 & 24 & 1 & 33 \\
Other land cover & 0 & 0 & 1 & 79 & 80 \\
Sum of samples & 242 & 679 & 65 & 94 & 1080 \\
\hline \multicolumn{7}{l}{ Overall accuracy $=93.14 \%$} & Kappa coefficient $=0.87$ \\
\hline
\end{tabular}

Table 6 reflects that, except for the Shiyan Prefecture, the carbon storage of the arbor layer of the coniferous forest obtained in this study was lower than that calculated on the basis of the field quadrate. This discrepancy indicates that the values of carbon storage were partially underestimated in this study given the following aspects. Firstly, the large area of Hubei Province, the considerable heterogeneity of forest structures and other characteristics of different prefectures may account for this discrepancy. The field samples can reflect heterogeneity with increased detail when compared with the remote sensing data. However, considering the unaffordable high cost, we can only obtain some samples of the forest population in the study area, but not the entire forest, thereby failing to reflect forest distribution absolutely. Secondly, given the influence of the atmosphere, the difference in sensor quality, and the data processing method, the remote sensing image itself had a certain error (overall accuracy was $93.14 \%$ ); thus, the extraction accuracy of our forest category was not $100 \%$, that is, it was not absolutely correct. Thirdly, although the definition and divisionary classification indicators of 
different forests can reflect their essential characteristics, selecting indicators still has some subjectivity. However, the difference between the two values was negligible with a relative error of less than $5 \%$. This finding indicates that the carbon storage in the arbor layer of the coniferous forest obtained in this study was highly accurate. Furthermore, this finding suggests that the results for carbon storage in the study were ideal and reliable.

Table 6. The relative errors of the tree canopy layer of coniferous forest between our study and calculated values based on the field measured data [27].

\begin{tabular}{cccc}
\hline Prefectures & $\begin{array}{c}\text { Carbon Storage of } \\
\text { Our Study (Tg) }\end{array}$ & $\begin{array}{c}\text { Carbon Storage Based the } \\
\text { Field Measurement Data (Tg) }\end{array}$ & Relative Error (\%) \\
\hline Enshi & 33.44 & 32.61 & -2.48 \\
Yichang & 28.26 & 27.83 & -1.52 \\
Shiyan & 23.05 & 24.06 & 4.38 \\
Xiangfan & 15.94 & 15.29 & -4.08 \\
Huanggang & 9.63 & 9.19 & -4.57 \\
Xiaogan & 2.52 & 2.45 & -2.78 \\
\hline
\end{tabular}

\subsection{Forest Distribution Extraction}

As shown in Figure 4, from the perspective of the effect, the forest information extracted by the OBIA technique was relatively smooth and compact and maintained a high distribution consistent with the actual forests with a clear boundary shape.

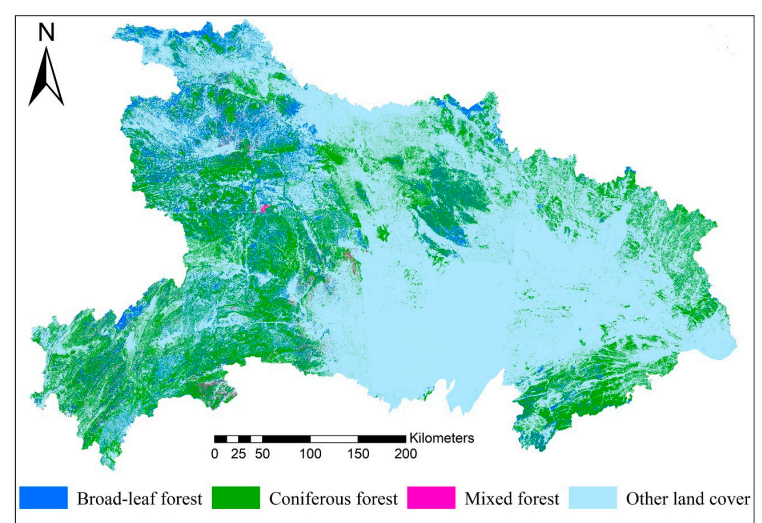

(a)

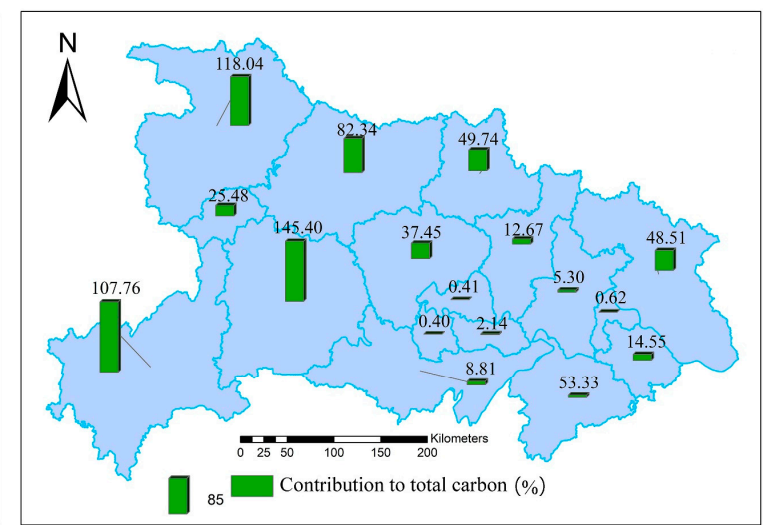

(b)

Figure 4. Spatial distribution of the forests (a) and forest carbon storage (b).

The total forest area of Hubei Province was $61,338.66 \mathrm{~km}^{2}$ in 2010 , accounting for $33.00 \%$ of the total area of the province. Amongst them, coniferous forests occupied the largest area, reaching $43,761.66 \mathrm{~km}^{2}$, accounting for $71.35 \%$ of the total forest area in Hubei Province. In second place was broadleaf forests, which covered an area of $15,556.80 \mathrm{~km}^{2}$, accounting for $25.36 \%$ of the total forest area in Hubei Province (Figure 5). The mixed forests occupied the smallest area (i.e., $2020.73 \mathrm{~km}^{2}$ ), accounting for only $3.29 \%$ of the total forest area in Hubei Province. 


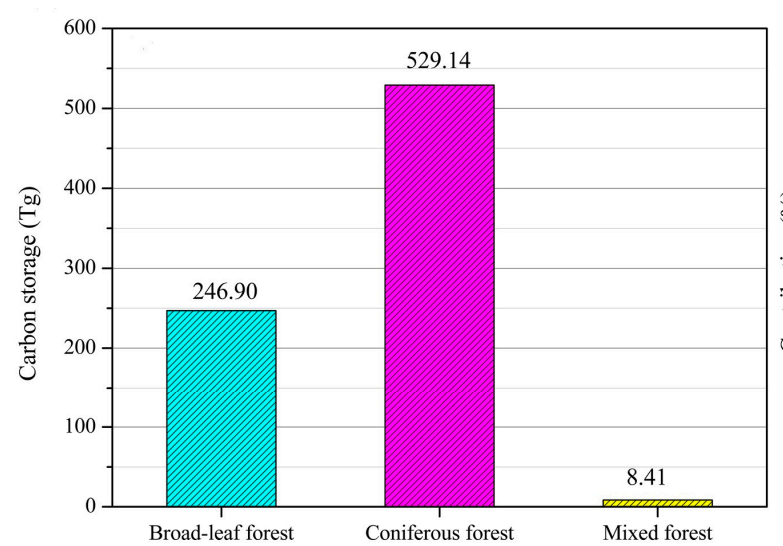

(a)

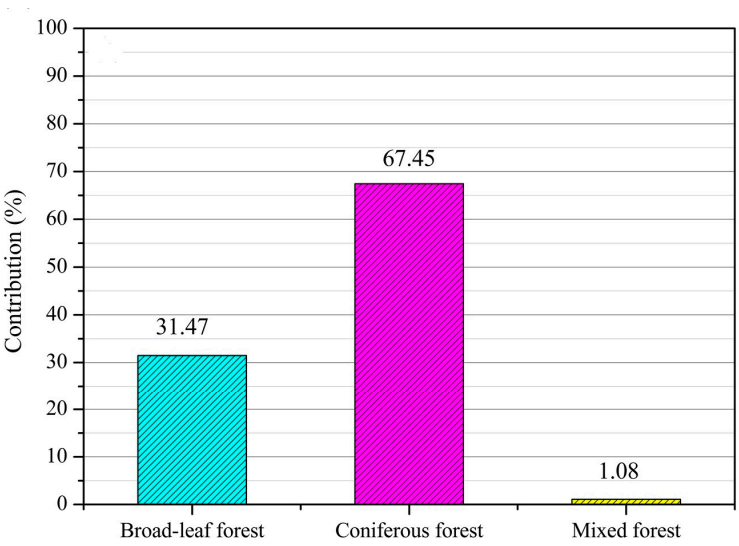

(b)

Figure 5. Carbon storage of broadleaf, coniferous and mixed forests (a) and the contribution of broadleaf, coniferous, and mixed forests to the total carbon storage (b).

\subsection{Total Carbon Storage and Spatial Pattern}

According to the calculation results, the total carbon storage in the forest ecosystem in Hubei Province was 784.46 Tg. Spatially, Enshi had the largest carbon storage, reaching $172.66 \mathrm{Tg}$ and accounting for $22.01 \%$ of the total forest carbon storage in Hubei Province. The second and third prefectures with the largest carbon storage were Yichang and Shiyan, whose carbon storage amounts were 147.01 and $119.32 \mathrm{Tg}$, accounting for $18.74 \%$ and $15.21 \%$ respectively. Qianjiang Prefecture had the smallest carbon reserve of only $0.40 \mathrm{Tg}$ (Figure $4 \mathrm{~b}$ ). The spatial pattern of carbon storage largely depends on forest distribution. In Hubei Province, forests are mainly distributed in the western region and are sparsely distributed in the central and eastern regions (Figure 4a). Among the prefectures, Enshi, Yichang, and Shiyan have the largest forest distributions of 13,517.16, 11,424.47, and $9315.61 \mathrm{~km}^{2}$, respectively, whereas Qianjiang Prefecture has the smallest forest area of only $30.4 \mathrm{~km}^{2}$.

\subsection{Contributions of the Different Types of Forests to Total Carbon Storage}

In the entire study area, the carbon reserves of the coniferous forests totaled $559.66 \mathrm{Tg}$, and their contribution to the total carbon reserves in the province were the largest, accounting for $71.34 \%$. The broadleaf forests followed, with a carbon storage of $198.96 \mathrm{Tg}$, contributing $25.36 \%$ to the total carbon storage in Hubei Province. The contribution rate of mixed forests to the forest carbon storage in Hubei Province was the smallest, reaching only 3.30\% (25.84 Tg) (Figure 5).

\subsection{Contributions of the Layers of Forest in the Vertical Direction to the Total Carbon Storage}

The carbon storage in the different vertical layers and their contributions to the total carbon reserves were also quantified. As shown in Figure 6, the forest soil layer presented the largest carbon storage, which had a controlling effect on the total carbon reserves of the forest, reaching $601.16 \mathrm{Tg}$ and contributing $76.63 \%$ to the total carbon reserves of the forest. The tree canopy layer ranks second. This layer, which has a large amount of biomass, had a carbon storage of $159.41 \mathrm{Tg}$, contributing $19.05 \%$ to the total forest carbon storage in Hubei Province. The carbon storage amounts in the shrub layer and litter layer were much smaller than those in the soil layer and tree canopy layer. The carbon storage in the shrub layer was $18.78 \mathrm{Tg}$, approximately $1 / 32$ of that in the soil layer and $1 / 8$ of that in the tree canopy layer, contributing only $2.39 \%$ to the total carbon storage in Hubei Province. The carbon storage in the litter layer was the smallest, amounting to only $15.10 \mathrm{Tg}$, which is approximately $1 / 40$ of that in the soil layer, $1 / 11$ of that in the tree canopy layer, and only $1.93 \%$ of the total forest carbon storage in Hubei Province. 


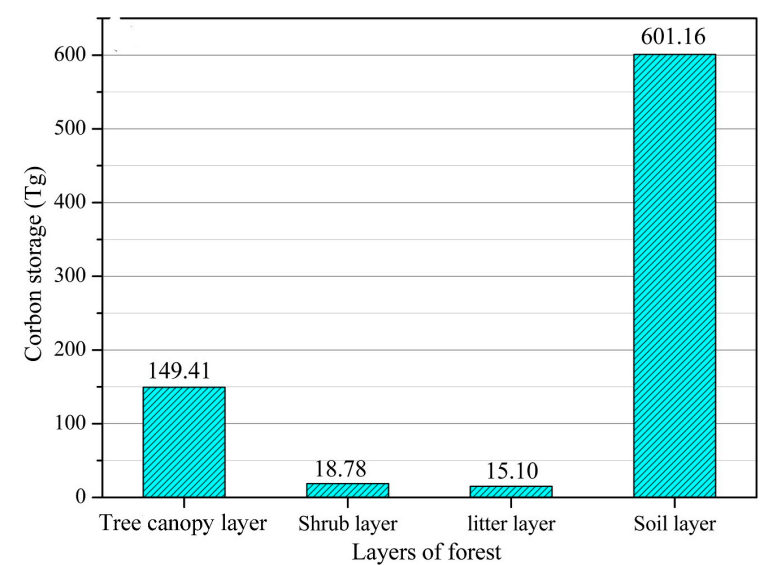

(a)

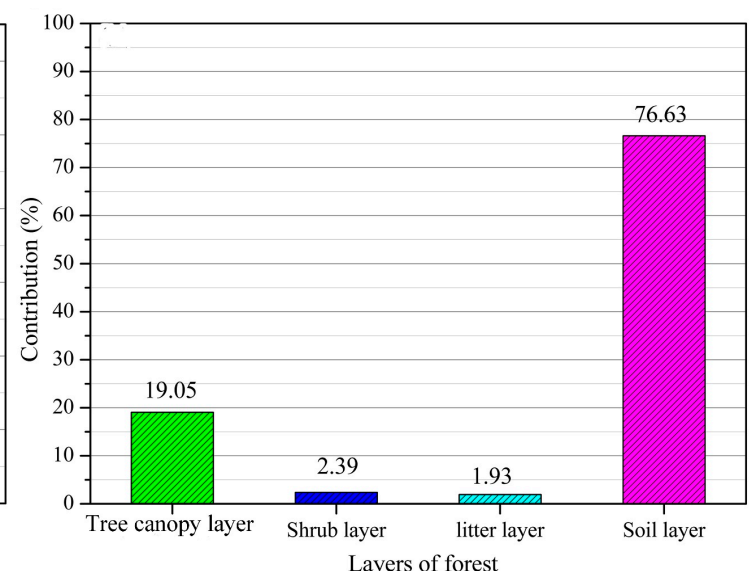

(b)

Figure 6. Carbon storage (Tg) in Hubei Province (a) and contribution rates (\%) of different forest layers in Hubei Province (b).

\subsection{Contributions of the Layers in Different Types of Forest to the Total Carbon Storage}

As shown in Figure 7, the soil layer in the broadleaf forests contributed the most to the carbon storage in Hubei Province, reaching $19.44 \%$ (152.47 Tg). The tree canopy layer and shrub layer possessed carbon storage amounts of 37.89 and $4.76 \mathrm{Tg}$ respectively, contributing $4.83 \%$ and $0.61 \%$ to the total forest carbon storage in the study area, respectively. The carbon storage amounts (contributions to the total forest carbon storage in the study area) in the soil, arbor, shrub, and litter layers in the coniferous forests were $28.89(54.67 \%), 106.60(13.59 \%), 13.40(1.71 \%)$, and $10.77 \mathrm{Tg}(1.37 \%)$, respectively. The carbon storage amounts in the arbor, shrub, litter, and soil layers in the mixed forests were 4.92, $0.62,0.50$, and $19.80 \mathrm{Tg}$, respectively, and their contributions to the total carbon storage in the study area were $0.62 \%, 0.08 \%, 0.06 \%$, and $2.52 \%$, respectively.

Overall, the different layers in the broadleaf, mixed, and coniferous forests showed the same trend in terms of their contributions to the total forest carbon storage in the area: soil layer $>$ tree canopy layer $>$ shrub layer $>$ litter layer. Amongst the soil layers, the soil layer in the coniferous forests contributed the most to the total carbon storage in the study area (i.e., $54.67 \%(428.89 \mathrm{Tg})$ ), followed by the soil layer in the broadleaf forests, but the soil layer in the mixed forests contributed the least. Amongst the tree canopy layers, the tree canopy layer in the coniferous forest contributed the most to the forest carbon reserves in the study area. The contributions of the shrub and litter layers to the forest carbon reserves in the study area also showed the same trend: coniferous forest $>$ broadleaf forest $>$ mixed forest.

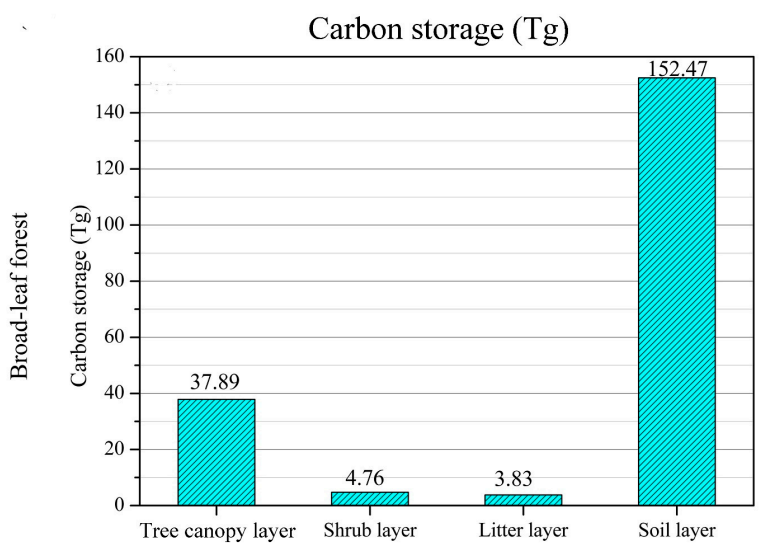

(a)

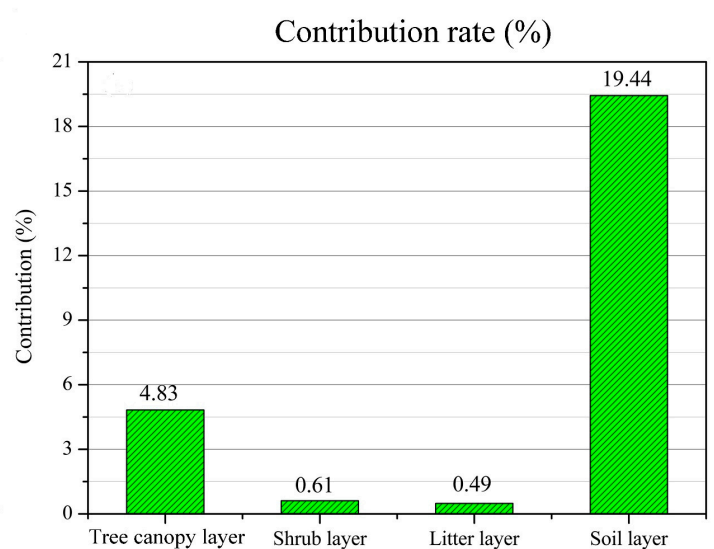

(b)

Figure 7. Cont. 


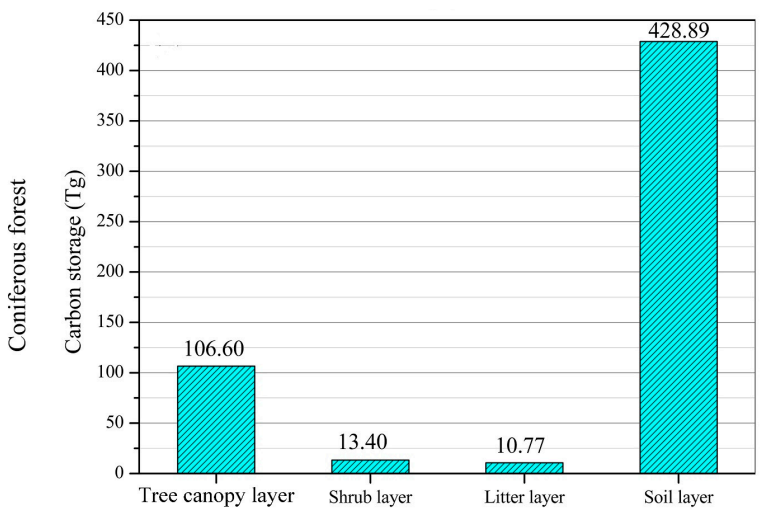

(c)

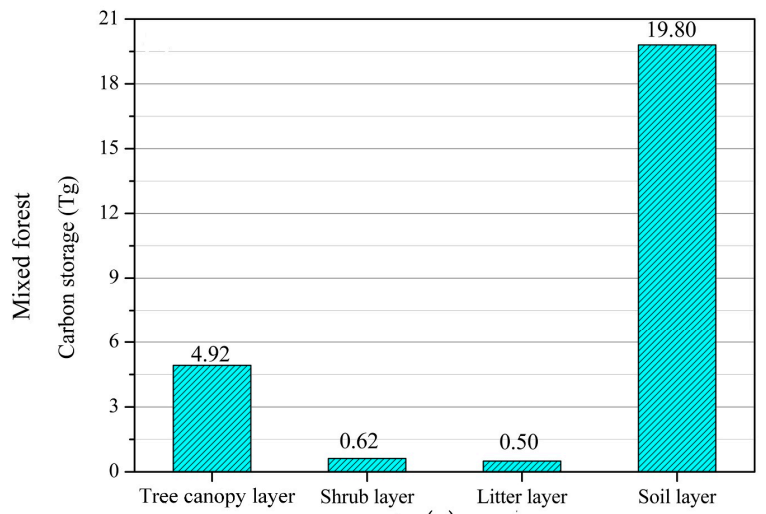

(e)

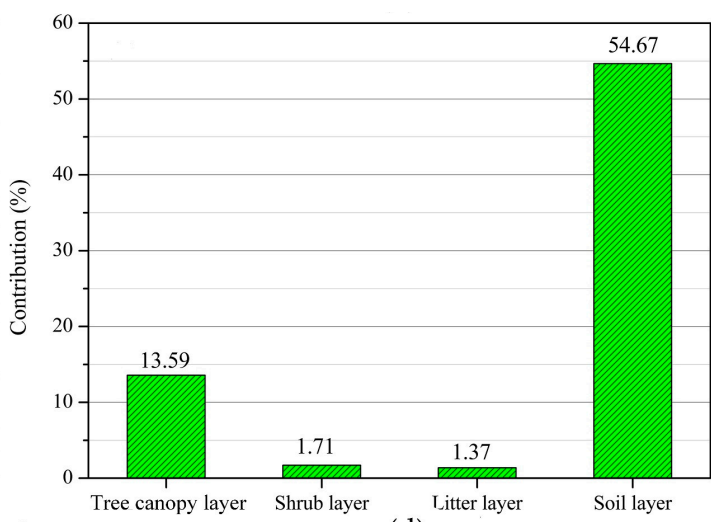

(d)

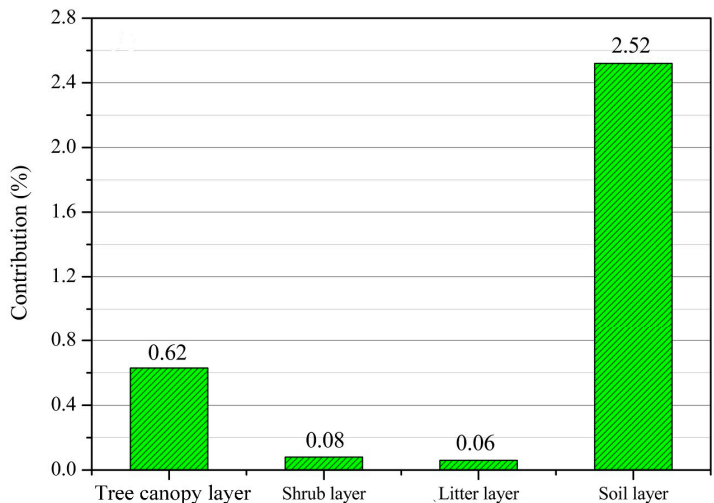

(f)

Figure 7. Carbon storage (Tg) in Hubei Province (a,c,e) and contribution rates $(\mathbf{b}, \mathbf{d}, \mathbf{f})$ of different layers in different types of forests to the total carbon storage in the study area.

\section{Discussion}

The OBIA technique extracts information on the basis of objects, a set of adjacent homogenous pixels, and objects have many important physical characteristics. Furthermore, the boundary shape is also more in line with the objective facts $[23,24]$. Therefore, the results of the forest extraction by the OBIA technique are smooth, compact, and consistent with the actual geological boundary. Moreover, the OBIA technique can not only use the spectral features of images, but also make full use of the spatial characteristics, texture, spatial structure, shape, and other characteristics [23,24]. Therefore, this technique can improve the extraction accuracy as it can, to a large extent, overcome the negative effects of the "same object with different spectra" and "different objects with the same spectrum", which are caused by using only the spectral features in traditional pixel-based methods [28,29]. The overall accuracy of the classification results was $93.10 \%$, and the Kappa coefficient was 0.89 , indicating that the classification results presented high precision and good effects.

The existing studies on carbon storage in forest ecosystems mainly focus on the tree canopy layer, and little attention is paid on other forest layers [30,31]. Doing so underestimates, to some extent, the carbon storage in the forest ecosystem. Vegetation layers under the canopy, litter layer, and soil layer are all important components of forest ecosystems and play an important role in the carbon sequestration of the forest ecosystem [32-34]. Our research attempts to characterize the spatial pattern of carbon storage in the forest ecosystem in both the vertical and horizontal directions. The results showed that the forest carbon storage in Hubei Province was $784.46 \mathrm{Tg}$, and the carbon storage amounts in the vegetation layers (including tree canopy layer, shrub layer, and litter layer) and soil layer were 183.30 and $601.16 \mathrm{Tg}$, respectively. The total forest carbon storage in China is $9240.50 \mathrm{Tg}$ [35]. By this standard, the forest carbon storage in Hubei Province accounted for $8.49 \%$ of that in China. However, the forest statistical area of China is $1,954,522 \mathrm{~km}^{2}$, and the forest area in Hubei Province only accounts for approximately $3.14 \%$ of that area [36,37]. In addition, shrubbery is frequently considered 
a forest type in the calculation of the total carbon storage on the national scale [38]. However, in this study, shrubbery was excluded as a forest type. Thus, carbon storage in the vegetation layers was underestimated, and the actual contribution may exceed $8.40 \%$. Carbon storage in the forest ecosystem in the Hubei Province is an important component of forest carbon storage in China.

The distribution of forest carbon storage is closely related to the distribution of forests [38,39]. Enshi, Yichang, Shiyan, and Xiangfan in the west of Hubei Province contributed the most to the total forest carbon storage in Hubei Province, with contribution rates of $18.73 \%, 13.89 \%, 15.21 \%$, and $10.61 \%$, respectively. This result is mainly because the forests in Hubei Province are mainly distributed in the west, and most of the forests are in the west for three main reasons. Firstly, the western mountainous region of Hubei Province is China's transition zone between the second and third terrain ladders and mainly includes the Wudang Mountains and the Daba Mountains, which consist of Shengnongjia, the Jing Mountain and the Wu Mountain [40-42]. These areas have had little interference from human activities and changes in the distribution of the original forest $[43,44]$. Secondly, the mountain vertical zone regulation is significant, leading to differences in rainfall, radiation, wind, water vapor transmission, factors such as soil shape differences in the vertical direction; these differences are attributed to the high altitude of the mountains, which has an average altitude of above $1000 \mathrm{~m}$ [19]. Thirdly, the western region of Hubei Province is the water source of China's South-to-North Water Transfer Project (SNWTP), and the Danjiangkou Reservoir, which is the starting point of the SNWTP, is located in this region. To ensure the quality of the water ecological environment and water diversion, the government has taken various measures to protect forests, including the prohibition of deforestation and the reduction of interference from human activities $[39,40]$.

Coniferous forests, followed by broadleaf and mixed forests, provided the major contributions to the total carbon reserves in the study area. This result is consistent with the findings of Hu et al. [41]. The carbon density of forest ecosystems is related to the composition, structure, and growth characteristics of forest vegetation. In addition, carbon storage in forest ecosystems is closely related to forest area [40]. The carbon sequestration rate of vegetation in coniferous forests is not as high as that of vegetation in broadleaf forests (Table 3) but is stable and persistent. Hence, the carbon density of coniferous forests is higher than that of broadleaf forests $[39,42]$. Meanwhile, coniferous forests are extensively distributed in Hubei Province and accounts for $71.35 \%$ of the total forest area of the province. Therefore, coniferous forests have the largest carbon storage and largest contribution to the forest carbon storage in Hubei Province. This also implies that Hubei Province has great potential for carbon sequestration. This is because Hubei Province has carried out large-scale conversion of farmland to forest and afforestation through ecological engineering since 2000, and the afforestation tree species are mainly coniferous forests [39]. The area of the broadleaf forest is smaller than that of the coniferous forest $\left(15,556.80 \mathrm{~km}^{2}\right.$ or $25.36 \%$ of the total forest area of Hubei Province). In addition, the carbon density of the broadleaf forest was larger than that of the mixed forest (Table 3). Therefore, the carbon reserves of the broadleaf forest are higher than those of the mixed forest, which ranked second.

The vegetation layers in this study included the arbor, shrub, and litter layers [5]. Generally speaking, the carbon storage in the forest vegetation layers was mainly from the influences of forest growth environment, forest age, forest type, and origin [6,39]. In this study, which used a remote sensing method, the carbon storage in the vegetation layers in Hubei Province was $183.30 \mathrm{Tg}$, which was higher than that in Hunan province (180.53 Tg) [15], much higher than that in Henan Province (100.61 Tg) [43], but significantly lower than those in Guangdong Province (215.55 Tg) and in Shanxi Province (238.52 Tg) [44,45]. This information indicates that carbon storage in the forest vegetation of Hubei Province plays an important role in carbon storage in China. Forest carbon reserves can be further increased through ecological engineering, such as afforestation. The vegetation layers in coniferous forests contributed the most $(16.67 \%(130.77 \mathrm{Tg}))$ to the total carbon storage in Hubei Province, followed by that of the broadleaf forests, which had a contribution rate of 5.93\% (46.49 Tg). The mixed forests had the least contribution. Therefore, the cultivation of mixed forests should be 
improved, and the healthy development of forest stands should be promoted in the future forest management process to enhance the forest carbon sink function of the region.

The contributions of the various vegetation layers in diverse types of forest to carbon storage in the study area considerably vary. The soil, arbor, litter, and shrub layers in the coniferous forests contributed the most to the total carbon storage in Hubei Province, with contribution rates of $54.57 \%$, $13.59 \%, 1.71 \%$, and $1.37 \%$, respectively. The contribution of each layer in the broadleaf forests to the total carbon storage of the study area is greater than that of the corresponding layer in the mixed forests. The different types of forest exhibit a stratification phenomenon, and large differences exist in the structure and function, resulting in vertical hierarchies and eventually leading to a huge difference in the carbon storage capacity $[17,46]$.

The carbon reserves in the soil layer in Hubei Province totaled $601.16 \mathrm{Tg}$, and its contribution to the total forest carbon storage in the study area was the largest, reaching $76.63 \%$, which is 3.28 times that of the vegetation layers. The results of the current study are approximate to that of Zhou et al. [47], indicating that the soil layer is indeed the largest carbon reservoir in the forest ecosystem of Hubei Province. Organic carbon is mainly concentrated in the soil and can be maintained for a long time because of slow turn speed; therefore, carbon deposits can be maintained for a long time and are protected by physical landscape [48,49]. However, carbon density, or the amount of carbon stored per unit area, is $99.54 \mathrm{t} \cdot \mathrm{hm}^{-2}$, which is well below the national average of $193.55 \mathrm{t} \cdot \mathrm{hm}^{-2}$. The low-carbon density of Hubei Province is mainly because the province is located in China's subtropical region, where rainfall is abundant and concentrated. Furthermore, the mountainous area is wide, and its slope is large; thus, its soil erosion resistance is poor. In addition, many forests in the study area are artificial forests, where the quantity and quality of the return forest litter are low, and the management measures on soil disturbance accelerate the decomposition of soil organic matter or erosion, leading to the loss of soil carbon [50,51].

The present study has several limitations. The main limitation of this study is the non-inclusion of the herb layer in the vegetation layers because of the lack of relevant data. Therefore, the total carbon storage in Hubei Province may be higher than the estimated value, and the contribution rates of the different layers may be lower than the estimated values. However, we found in our three field sampling campaigns across Hubei Province that the herb layers under the forest are few, and most were simply litter layers. Therefore, ignoring the herbaceous layer has negligible effects on the results and conclusions. Meanwhile, remote sensing methods, instead of the field measurement method, were mainly adopted. Remote sensing methods are known to introduce certain errors in data acquisition, image processing, and other processes. Therefore, the present results will have certain errors. However, the spatial pattern of carbon reserves was mainly analyzed on the macroscale. This approach is one advantage of the remote sensing method over the field measurement method. Finally, the extraction accuracy of the forest information is extremely high. Therefore, the present results are accurate and reliable. In future studies, obtaining more measured data on a large scale will further improve the results.

\section{Conclusions}

Based on HJ-CCD remote sensing imagery and published field sampling data, we explored the variation in carbon in a provincial forest ecosystem in the vertical and horizontal directions. The following conclusions are drawn from this study:

(1) The carbon storage in the forest ecosystem in Hubei Province was $784.46 \mathrm{Tg}$. The forest carbon storage in Hubei Province assumes an important position in China, but this storage must still be improved considerably. Spatially, the Enshi Prefecture contributed the most, followed by Yichang, Shiyan, and Xiangfan. In terms of contribution, the coniferous forests contributed the most to the total carbon storage in forests, with a contribution rate of $71.34 \%$, followed by the broadleaf and mixed forests. This result is attributed to the distribution of different types of forests in Hubei Province. Moreover, this finding implies that Hubei Province has considerable potential for carbon 
sequestration because the coniferous forests will continuously increase given a series of ecological projects implemented by the government.

(2) The stratification of forest carbon storage in the vertical direction was apparent in Hubei Province, that is, soil layer $>$ arbor layer $>$ shrub layer $>$ litter layer. Soil layer had the largest carbon storage and contributed the most (76.63\%), followed by the arbor layer, which accounted for $19.05 \%$ of the total carbon storage. However, the contribution rates of the shrub and litter layers to the total carbon reserves in Hubei Province were only $2.39 \%$ and $1.93 \%$, respectively. These results were mainly attributed to the environmental differences in the vertical direction of forest ecosystems, thereby indicating that the arbor forest vegetation in Hubei province plays an important role in forest carbon storage and improving forest carbon sink function.

(3) The contributions of the different forest layers in the coniferous, broadleaf, and mixed forests to the total carbon storage showed the same trend, that is, soil layer $>$ arbor layer $>$ litter layer $>$ shrub layer. The arbor, shrub, litter, and soil layers of the coniferous forests contributed the most to the forest carbon storage in Hubei Province, with contribution rates of $13.59 \%, 1.71 \%, 1.37 \%$, and $54.67 \%$, correspondingly.

Supplementary Materials: The following are available online at http:/ / www.mdpi.com/2072-4292/11/7/788/s1, Table S1: The ecosystem classification system established by Zhang et al. based on relevant international achievements and China's actual situation.

Funding: This research was funded by the National Natural Science Foundation of China (Grant No. 41801200), the Foundation of the Ministry of Culture and Tourism of China (Grant No. 18TAAG018), the Start-Up Foundation for Introducing Talent of NUIST (Grant No. 2017r091), and the College Students Practicing Innovation Training Program of NUIST (Grant No. 201810300096X).

Acknowledgments: I would like to thank the China Resources Satellite Application Center for providing some of the reference data. I would also like to thank the anonymous reviewers and members of the editorial team for their comments and contributions.

Conflicts of Interest: The author declare no conflict of interest.

\section{References}

1. Pan, Y.; Chen, J.M.; Birdsey, R.; McCullough, K.; He, L.; Deng, F. Age structure and disturbance legacy of North American forests. Biogeosciences 2011, 8, 715-732. [CrossRef]

2. Yude, P.; Birdsey, R.A.; Jingyun, F.; Richard, H.; Kauppi, P.E.; Kurz, W.A.; Phillips, O.L.; Anatoly, S.; Lewis, S.L.; Canadell, J.G. A large and persistent carbon sink in the world's forests. Science 2011, 333, 988-993.

3. Ogle, K. Hyperactive soil microbes might weaken the terrestrial carbon sink. Nature 2018, 560, 32-33. [CrossRef] [PubMed]

4. Tollefson, J. Grassland plants show surprising appetite for carbon dioxide. Nature 2018, 19. [CrossRef]

5. Rawlik, M.; Kasprowicz, M.; Jagodzinski, A.M. Differentiation of herb layer vascular flora in reclaimed areas depends on the species composition of forest stands. Forest Ecol. Manag. 2018, 409, 541-551. [CrossRef]

6. Loranty, M.M.; Berner, L.T.; Taber, E.D.; Kropp, H.; Natali, S.M.; Alexander, H.D.; Davydov, S.P.; Zimov, N.S. Understory vegetation mediates permafrost active layer dynamics and carbon dioxide fluxes in open-canopy larch forests of northeastern Siberia. PLoS ONE 2018, 13, e0194014. [CrossRef]

7. Zhang, T.; Niinemets, Ü.; Sheffield, J.; Lichstein, J.W. Shifts in tree functional composition amplify the response of forest biomass to climate. Nature 2018, 556, 99-102. [CrossRef]

8. Van, G.N.; Shi, Z.; van Groenigen, K.J; Osenberg, C.W.; Andresen, L.C.; Dukes, J.S.; Hovenden, M.J.; Luo, Y.; Michelsen, A.; Pendall, E. Predicting soil carbon loss with warming. Nature 2018, 554, E4-E5.

9. Safari, A.; Sohrabi, H.; Powell, S.; Shataee, S. A comparative assessment of multi-temporal Landsat 8 and machine learning algorithms for estimating aboveground carbon stock in coppice oak forests. Int. J. Remote Sens. 2017, 38, 6407-6432. [CrossRef]

10. Yan, E.; Lin, H.; Wang, G.; Sun, H. Improvement of forest carbon estimation by integration of regression modeling and spectral unmixing of Landsat data. IEEE Geosci. Remote Sens. Lett. 2015, 12, 2003-2007. 
11. Asner, G.P.; Brodrick, P.G.; Philipson, C.; Vaughn, N.R.; Martin, R.E.; Knapp, D.E.; Heckler, J.; Evans, L.J.; Juckes, T.; Goossens, B.; et al. Mapped aboveground carbon stocks to advance forest conservation and recovery in Malaysian Borneo. Biol. Conserv. 2018, 217, 289-310. [CrossRef]

12. Dai, W.; Fu, W.J.; Jiang, P.K.; Zhao, K.L.; Li, Y.H.; Tao, J.X. Spatial pattern of carbon stocks in forest ecosystems of a typical subtropical region of southeastern China. Forest Ecol. Manag. 2018, 409, 288-297. [CrossRef]

13. Hu, H.F.; Yang, Y.H.; Fang, J.Y. Toward accurate accounting of ecosystem carbon stock in China's forests. Sci. Bull. 2016, 61, 1888-1889.

14. Wang, Y.F.; Liu, L.; Shangguan, Z.P. Dynamics of forest biomass carbon stocks from 1949 to 2008 in Henan Province, east-central China. J. For. Res. 2018, 29, 439-448. [CrossRef]

15. Liu, Z.D.; Li, B.; Xi, F.; Xiang, W.H.; Tian, D.L.; Yan, W.D.; Lei, P.F. Dynamic characteristics of forest carbon storage and carbon density in the Hunan Province. Acta Ecol. Sin. 2016, 36, 6897-6908.

16. Song, C.; Zhang, Y.; Mei, Y.; Liu, H.; Zhang, Z.; Zhang, Q.; Zha, T.; Zhang, K.; Huang, C.; Xu, X. Sustainability of forests created by China's sloping land conversion program: A comparison among three sites in Anhui, Hubei and Shanxi. Forest Policy Econ. 2014, 38, 161-167. [CrossRef]

17. Vivanco, L.; Rascovan, N.; Austin, A.T. Plant, fungal, bacterial, and nitrogen interactions in the litter layer of a native Patagonian forest. PeerJ 2018, 6, 1-18. [CrossRef]

18. Liu, Y.L.; Cai, E.X.; Jing, Y.; Gong, J.; Wang, Z.Y. Analyzing the decoupling between rural-to-urban migrants and urban land expansion in Hubei Province, China. Sustainability 2018, 10, 345. [CrossRef]

19. Wang, X.R.; Pang, H.D.; Zheng, L.Y.; Cui, H.X. Carbon storage and carbon density of forest ecosystems in Hubei Province. J. Cent. South Univ. For. Technol. 2015, 35, 93-98.

20. Chen, B.Q.; Wu, Z.X.; Wang, J.K.; Dong, J.W.; Guan, L.M.; Chen, J.M.; Yang, K.; Xie, G.S. Spatio-temporal prediction of leaf area index of rubber plantation using HJ-1A/1B CCD images and recurrent neural network. ISPRS J. Photogramm. Remote Sens. 2015, 102, 148-160. [CrossRef]

21. Pang, H.; Wang, X.; Zhang, J.; Zheng, L.; Cui, H. Characteristics of Carbon storage and carbon density of pinus massoniana natural forests in Hubei Province, China. J. Northeast For. Univ. 2014, 7, 40-43.

22. Zhang, L.; Wu, B.F.; Li, X.S.; Xing, Q. Classification system of China land cover for carbon budget. Acta Ecol. Sin. 2014, 34, 7158-7166.

23. Iabchoon, S.; Wongsai, S.; Chankon, K. Mapping urban impervious surface using object-based image analysis with WorldView-3 satellite imagery. J. Appl. Remote Sens. 2017, 11, 046015. [CrossRef]

24. Lu, M.; Chen, J.; Tang, H.J.; Rao, Y.H.; Yang, P.; Wu, W.B. Land cover change detection by integrating object-based data blending model of Landsat and MODIS. Remote Sens. Environ. 2016, 184, 374-386. [CrossRef]

25. Blaschke, T.; Hay, G.J.; Kelly, M.; Lang, S.; Hofmann, P.; Addink, E.; Feitosa, R.Q.; Meer, F.V.D.; Werff, H.V.D.; Coillie, F.V. Geographic object-based image analysis-A towards a new paradigm. ISPRS J. Photogramm. Remote Sens. 2014, 87, 180-191. [CrossRef]

26. Ma, L.; Li, M.; Ma, X.; Cheng, L.; Du, P.; Liu, Y. A review of supervised object-based land-cover image classification. ISPRS J. Photogramm. Remote Sens. 2017, 130, 277-293. [CrossRef]

27. Zhao, Y.S. Principle and Method of Remote Sensing Application and Analysis; Science Press of China: Beijing, China, 2012; pp. 203-208.

28. Georganos, S.; Grippa, T.; Vanhuysse, S.; Lennert, M.; Shimoni, M.; Wolff, E. Very high-resolution object-based land use-land cover urban classification using extreme gradient boosting. IEEE Geosci. Remote Sens. Lett. 2017, 15, 607-611. [CrossRef]

29. Zhang, X.D.; Chen, G.Z.; Wang, W.B.; Wang, Q.; Dai, F. Object-based land-cover supervised classification for very-high-resolution UAV Images using stacked denoising autoencoders. IEEE J. Sel. Top. Appl. Earth Obs. Remote Sens. 2017, 10, 3373-3385. [CrossRef]

30. Liu, X.Q.; Liang, M.J.; Chen, L.C.; Wang, S.L.; Yang, H.J. Carbon storage, carbon density and spatial distribution of forest ecosystems in hunan province. Chin. J. Ecol. 2017, 36, 2385-2393.

31. Li, P.; Zhu, J.; Hu, H.; Guo, Z.; Pan, Y.; Birdsey, R.; Fang, J. The relative contributions of forest growth and areal expansion to forest biomass carbon. Biogeosciences 2016, 12, 9587-9612. [CrossRef]

32. Pan, Y.; Birdsey, R.A.; Phillips, O.L.; Jackson, R.B. The structure, distribution, and biomass of the world's forests. Ann. Rev. Ecol. Evol. Syst. 2013, 44, 593-622. [CrossRef]

33. He, N.; Wen, D.; Zhu, J.; Tang, X.; Xu, L.; Zhang, L.; Hu, H.; Huang, M.; Yu, G. Vegetation carbon sequestration in Chinese forests from 2010 to 2050. Glob. Chang. Biol. 2017, 23, 1575-1584. [CrossRef] 
34. Guo, Z.D.; Hu, H.F.; Pan, Y.D.; Birdsey, R.A.; Fang, J.Y. Increasing biomass carbon stocks in trees outside forests in China over the last three decades. Biogeosciences 2014, 11, 4115-4122. [CrossRef]

35. Zhao, M.; Yue, T.; Na, Z.; Sun, X.; Zhang, X. Combining LPJ-GUESS and HASM to simulate the spatial distribution of forest vegetation carbon stock in China. J. Geogr. Sci. 2014, 24, 249-268. [CrossRef]

36. Xu, L.; Shi, Y.; Fang, H.; Zhou, G.; Xu, X.; Zhou, Y.; Tao, J.; Ji, B.; Xu, J.; Li, C. Vegetation carbon stocks driven by canopy density and forest age in subtropical forest ecosystems. Sci. Total Environ. 2018, 631, 619-626. [CrossRef] [PubMed]

37. China, S.B. Hubei Statistical Yearbook for 2010; China Statistics Press: Beijing, China, 2011; pp. 345-476.

38. Fang, J.; Chen, A.; Peng, C.; Zhao, S.; Ci, L. Changes in forest biomass carbon storage in China between 1949 and 1998. Science 2001, 292, 2320-2322. [CrossRef] [PubMed]

39. Lu, F.; Hu, H.; Sun, W.; Zhu, J.; Liu, G.; Zhou, W.; Zhang, Q.; Shi, P.; Liu, X.; Wu, X. Effects of national ecological restoration projects on carbon sequestration in China from 2001 to 2010. Proc. Natl. Acad. Sci. USA 2018, 115, 4039-4044. [CrossRef] [PubMed]

40. Pao, S.L. The Carbon balance of terrestrial ecosystems in China. China Basic Sci. 2010, 458, 1009-1013. [CrossRef] [PubMed]

41. Qing, H.; Silong, W.; Longchi, C.; Weidong, Z.; Chao, G. Biomass and carbon density of main forest ecosystems in Hubei Province. Chin. J. Ecol. 2012, 31, 1626-1632.

42. Liu, W.; Lu, F.; Luo, Y.; Bo, W.; Kong, L.; Zhang, L.; Liu, B.; Ouyang, Z.; Wang, X. Human influence on the temporal dynamics and spatial distribution of forest biomass carbon in China. Ecol. Evol. 2017, 7, 6220-6230. [CrossRef] [PubMed]

43. Yiming, L. Forest carbon storage and development trend in Henan province. Innov. Sci. Technol. 2012, 4, 18-19.

44. Ye, J.S.; She, G.H. Forest carbon dynamics in Guangdong province. J. Nanjing For. Univ. 2010, 34, 7-12.

45. Qi, M.A.; Liu, K.; Zhang, H. Carbon Storage by Forest Vegetation and Its Spatial Distribution in Shaanxi. Resour. Sci. 2012, 34, 1781-1789.

46. Haughian, S.R.; Burton, P.J. Microclimate differences above ground-layer vegetation in lichen-dominated pine forests of north-central British Columbia. Agric. Forest Meteorol. 2018, 249, 100-106. [CrossRef]

47. Yurong, Z.; Liangzhen, Y.; Shidong, Z. Carbon storage and budget of major Chinese forest types. Acta Phytoecol. Sin. 2000, 24, 518-522.

48. Jandl, R.; Lindner, M.; Vesterdal, L.; Bauwens, B.; Baritz, R.; Hagedorn, F.; Johnson, D.W.; Minkkinen, K.; Byrne, K.A. How strongly can forest management influence soil carbon sequestration? Geoderma 2007, 137, 253-268. [CrossRef]

49. Jolivet, C.; Arrouays, D.; Lévèque, J.; Andreux, F.; Chenu, C. Organic carbon dynamics in soil particle-size separates of sandy spodosols when forest is cleared for maize cropping. Eur. J. Soil Sci. 2010, 54, 257-268. [CrossRef]

50. Guoyi, Z.; Shuguang, L.; Zhian, L.; Deqiang, Z.; Xuli, T.; Chuanyan, Z.; Junhua, Y.; Jiangming, M. Old-growth forests can accumulate carbon in soils. Science 2006, 314, 1417.

51. Nagy, R.C.; Porder, S.; Brando, P.; Davidson, E.A.; Figueira, A.M.E.S.; Neill, C.; Riskin, S.; Trumbore, S. Soil carbon dynamics in soybean cropland and forests in Mato Grosso, Brazil. J. Geophys. Res. Biogeosci. 2018, 123, 18-31. [CrossRef]

(c) 2019 by the author. Licensee MDPI, Basel, Switzerland. This article is an open access article distributed under the terms and conditions of the Creative Commons Attribution (CC BY) license (http:// creativecommons.org/licenses/by/4.0/). 